\author{
Kamila Kaźmierczak $^{1}$, Joanna Kufel-Grabowska ${ }^{1,2}$, Tomasz Kozłowski ${ }^{3}$, Błażej Nowakowski ${ }^{1,4}$ \\ ${ }^{1}$ Department of Surgical, Oncological and Endoscopic Gynaecology, Greater Poland Cancer Centre, Poznan, Poland \\ ${ }^{2}$ Department of Electroradiology, Poznan University of Medical Sciences, Poznan, Poland \\ ${ }^{3}$ Department of Anaesthesiology and Intensive Care, Greater Poland Cancer Centre, Poznan, Poland \\ ${ }^{4}$ Department of Cancer Pathology and Prophylaxis, Poznan University of Medical Sciences, Poznan, Poland
}

\title{
When to say "no" to a patient with an ovarian tumour and in poor general condition?
}

Address for correspondence:

Lek. Kamila Kaźmierczak

Oddział Ginekologii Operacyjnej,

Onkologicznej i Endoskopowej

Wielkopolskie Centrum Onkologii

ul. Garbary 15, 61-866 Poznań

e-mail:kamilka35@icloud.com

Oncology in Clinical Practice 2019, Vol. 15, No. 2, 132-134 DOI: 10.5603/OCP.2019.0018

Translation: dr Elżbieta Stelmaszczyk

Copyright (C) 2019 Via Medica

ISSN 2450-1654

\begin{abstract}
Neuroendocrine tumours (NET) originating from the ovary are very rare, constituting about $0.52-1.7 \%$ of all NETs. Primary carcinoids constitute about $0.1 \%$ of ovarian tumours and $0.3 \%$ of all carcinoids. They rarely show hormonal activity. They are most often diagnosed post-operatively, based on pathomorphological examination using immunohistochemical methods. Due to the small number of cases, most information on the management of patients with this diagnosis comes from retrospective studies and case reports.

This paper presents a case report of a 63-year-old woman who was admitted to the department of surgical gynaecology with the diagnosis of a 15-cm right ovary tumour. Her general condition was poor due to severe respiratory failure and severe tricuspid valve insufficiency. The clinical picture and the performed echocardiographic examination aroused the suspicion of carcinoid heart disease (Hedinger syndrome - a cardiological syndrome of carcinoids). Due to the determination and cooperation of a multidisciplinary medical team, despite a very bad prognosis, the patient underwent surgery. Immediately after the operation, the patient's condition was critical, but it gradually improved. In the postoperative pathomorphological examination, a highly differentiated neuroendocrine tumour (grade 1 - G1) was diagnosed at stage IA according to the FIGO classification. The patient was referred to the endocrinology department, where receptor scintigraphy was performed without revealing other tumour changes. The patient did not require adjuvant therapy. Making a decision about surgical treatment of a patient in poor physical condition with a possibly reversible cause of heart failure was the right thing to do, and it allowed her to return to normal physical activity.

Key words: neuroendocrine tumour, carcinoid syndrome, carcinoid heart disease, Hedinger syndrome
\end{abstract}

Oncol Clin Pract 2019; 15, 2: 132-134

\section{Introduction}

Neuroendocrine tumours (NET) of the ovary occur very rarely, constituting $0.52-1.72 \%$ of all NETs [1]. Primary carcinoids constitute about $0.1 \%$ of ovarian tumours and $0.3 \%$ of all carcinoids [2]. Among primary neuroendocrine ovarian tumours, there are carcinoids, large-cell carcinomas, and small-cell carcinomas of the hypercalcaemic and lung type [3]. These diseases are divided based on the FIGO classification. In over half of these cases, carcinoids are diagnosed at an early stage and the prognosis is very good at that time with five-year survival of over $90 \%$ [4]. At more advanced stages, survival is much worse, and only $33 \%$ of the patients survive for over five years [5].

Neuroendocrine tumours are usually located in the digestive tract $(75-85 \%)$, and more rarely pertain to the respiratory system (15-25\%). Most of them show no clinical symptoms and are diagnosed incidentally. In $20-30 \%$ of the patients, the first symptoms are related to the production of hormones, which enables the diagnosis of carcinoid syndrome. The most common 
symptoms of carcinoid syndrome include flushing and diarrhoea, along with symptoms of bronchospasm and heart damage. These symptoms are related to the hypersecretion of serotonin, and other active substances, and occur in the case of significantly advanced disease in patients with liver metastases [6]. In the case of liver failure due to the presence of metastases, an excess of serotonin flows into the right heart directly with venous flow. The precise pathomechanism of serotonin-induced valve damage is not known - the visible effect is the appearance of lesions mainly in the endocardium and the endothelial layer of large vessels, which manifest as sharply delineated fibrous thickening. These lesions cause morphological, and subsequently mechanical, damage to the valves, mainly those of the right heart, which leads, most often, to regurgitation (and less often to tricuspid stenosis). Cardiological damage is seen in $50 \%$ of patients with carcinoid syndrome and it significantly worsens their prognosis due to progressive right-heart failure.

Cardiological carcinoid syndrome (Hedinger syndrome) without other clinical symptoms exists unusually seldom. In the case of the presented patient with a tumour of the right ovary, venous blood flows directly from the inferior vena cava, omitting the portal circulatory system, due to which an excess of serotonin is not metabolised by the hepatocytes, causing "right heart" damage.

\section{Case report}

In November 2017, a 63-year-old patient with diagnosis of a tumour of the right ovary, with a diameter of $15 \mathrm{~cm}$, was referred to the Gynaecology Clinic of the Greater Poland Oncology Centre to be qualified for surgical treatment. The patient was in intermediate overall condition, and peripheral cyanosis along with abdominal swelling and swelling of the limbs was notable. The patient complained of dyspnoea on exertion, and increased concentration of CA-125 (cancer antigen-125; $88.66 \mathrm{u} / \mathrm{ml}$ ) as well as HE4 (human epididymis protein; $159.50 \mathrm{pmol} / \mathrm{l}$ ) was found. On gynaecological and vaginal sonographic examination, the presence of a right ovarian tumour was confirmed, with a diameter of $15 \mathrm{~cm}$, which, due to its size, constituted an absolute indication for surgical treatment. Sonographic examination of the uterus and left adnexa was insignificant. The patient was referred to a cardiology ward for a full evaluation of the cardiovascular system. Within three weeks of the gynaecological consultation, the patient's overall condition deteriorated significantly - respiratory insufficiency, lower body oedema, and peripheral cyanosis worsened and central cyanosis appeared. The patient was unable to function independently and spent most of her days in a half-sitting position. An echocardiogram revealed severe tricuspid regurgitation, a lack of flap coaptation, and normal ventricular systolic activity. Peripheral blood saturation was $80 \%$. The general clinical picture raised suspicion of carcinoid heart disease. A rise in markers was also observed, with the values being Ca-125 (133 U/ml) and HE4 (496 pmol/l). Bilateral renal retention was found, with ureteral widening, and the presence of free fluid in the lesser pelvis.

The most likely cause of worsening right ventricular insufficiency was pressure on the inferior vena cava cause by a massive tumour of the right ovary; due to this, the patient was transferred to the oncological gynaecology ward. The patient was qualified for a life-saving procedure, having been informed of the high risk of perioperative complications. Anaesthesia and perioperative care for this patient constituted a complex medical problem, because - as well as right ventricular insufficiency - symptoms resulting from pressure on the inferior vena cava were present. Before the procedure, a detailed risk assessment according to the NSQIP (National Surgical Quality Improvement Program) was done - the risk of serious complications, including death, was estimated at $22.7 \%$. The results were discussed during a meeting of the team of gynaecologists and anaesthesiologists, the patient and her family were also informed on the above results. When making the decision to operate, the fact that the planned surgical procedure, despite a high risk of complications, was the only possibility of treating the cause, and ultimately made a final diagnosis possible. The removal of the pressure on the vena cava caused by the tumour was a condition for any possible cardiosurgical treatment.

After the procedure, the patient's overall condition was severe - she spent 16 days in the intensive care unit, including nine days of sedation, she was intubated, ventilated mechanically - with an oxygen concentration up to $65 \%$ - and also required pharmacological support of the cardiovascular system, as well as diuresis stimulation. A gradual improvement of overall condition was observed. At the time of transfer to the gynaecological ward, the patient was cardiovascularly stable, breathed without dyspnoea even in supine position, was supported with passive oxygen therapy only at times, and had a blood oxygen saturation of $95 \%$. In the final pathological testing, a highly-differentiated (G1) NET of the right ovary was found. On the $20^{\text {th }}$ day after surgery, the patient was transferred to the endocrinology department, where imaging was performed. An octreoscan did not reveal the presence of NET focal lesions, the patient did not require adjuvant treatment. The patient's general condition improved significantly, and the symptoms of inferior vena cava syndrome withdrew. 


\section{Discussion}

The average lifespan of patients with cardiac carcinoid syndrome, with symptoms of moderate and severe cardiac insufficiency (NYHA III/IV), is about 11 months. Most patients die due to progressive heart failure due to tricuspid valve regurgitation. The average delay in cardiosurgical treatment due to the lack of clear guidelines for invasive treatment of Hedinger syndrome amounts to 24 months, which significantly worsens the prognosis [7]. Currently, based on a 20-year observation of over 200 patients with cardiac carcinoid syndrome at the Mayo Clinic in the USA, it is thought that early surgical intervention in this group of patients may increase their chances of survival [8]. Three-year survival is noted amongst $31 \%$ of patients with cardiac carcinoid syndrome, compared to $60 \%$ for those without cardiological involvement [9].

The main clinical symptoms in the patient discussed here were those of severe right-heart failure and inferior vena cava syndrome, which made surgical intervention a high-risk path. The echocardiographic imaging could have suggested carcinoid heart disease; however, a lack of general symptoms caused by an excess of serotonin suggested a different cause for "right heart" damage. According to the latest guidelines by the Polish Neuroendocrine Tumour Network (Polska Sieć Guzów Neuroendokrynnych) from 2017 regarding the diagnostics and treatment of patients with neuroendocrine tumours, chromogranin concentration is no longer recommended as routine testing, and the serial assessment of chromogranin may be useful for monitoring the course of the disease. In carcinoid syndrome, 5-hyrdoxyindoloacetic acid concentration is used [10].

The symptoms of carcinoid syndrome were not present in our patient, and the rise of CA-125 and HE4 markers, along with the presence of free fluid in the pelvic cavity, suggested a malignant tumour typical of the ovary. Imaging tests showed no traits of dissemination, which was an argument for taking on the risk of surgery. Considering the possibility of cardiosurgical treatment after the symptoms of inferior vena cava syndrome have subsided, it was decided that an excision of the tumour would be performed. This decision was extremely risky, but an attempt at the procedure gave a chance for remission, or a prognosis improvement, while further symptomatic treatment would have ended up in a rapid death. Although symptomatic treatment with diuretics, digoxin, and limiting the intake of fluids and sodium may alleviate the symptoms of right-heart failure at first, they do not improve the final prognosis. Removal of the primary tumour may be associated with the patient's complete recovery but will not undo the valve damage $[11,12]$. The only effective treatment of valve defects due to carcinoid syndrome is cardiosurgical treatment consisting of valve replacement surgery, which decreases the symptoms and increases quality of life. In the case of the presented patient, an active approach caused significant improvement in her overall condition, and thanks to the pathological diagnosis further cardiosurgical treatment is possible. The patient is currently awaiting cardiac surgery.

\section{References}

1. Soga J, Osaka M, Yakuwa Y. Carcinoids of the ovary: an analysis of 329 reported cases. J Exp Clin Cancer Res. 2000; 19(3): 271-280, indexed in Pubmed: 11144518

2. Talerman A. Germ cell tumor of the ovary. W: Blaunstein's pathology of the female genital tract Kurman R (red). Springer-Verlag, New York 1993: 886-893.

3. Kuc-Rajca M, Dańska-Bidzińska A. Współczesne zasady leczenia nowotworów neuroendokrynnych kobiecych narządów płciowych. Ginekol Pol. 2011; 82: 685-689.

4. Soga J. Carcinoids and their variant endocrinomas. An analysis of 11842 reported cases. J Exp Clin Cancer Res. 2003; 22(4): 517-530, indexed in Pubmed: 15053292

5. Modlin IM, Lye KD, Kidd M. A 5-decade analysis of 13,715 carcinoid tumors. Cancer. 2003; 97(4): 934-959, doi: 10.1002/cncr.11105. indexed in Pubmed: 12569593

6. Młodzianowski A. Zespół Hedingera - sercowe objawy zespołu rakowiaka. Choroby Serca i Naczyń. 2014; 11: 34-38.

7. Connolly HM, Nishimura RA, Smith $\mathrm{HC}$, et al. Outcome of cardiac surgery for carcinoid heart disease. J Am Coll Cardiol. 1995; 25(2): 410-416, indexed in Pubmed: 7829795

8. Møller JE, Pellikka PA, Bernheim AM, et al. Prognosis of carcinoid heart disease: analysis of 200 cases over two decades. Circulation. 2005; 112(21): 3320-3327, doi: 10.1161/CIRCULATIONAHA.105.553750, indexed in Pubmed: 16286584

9. Pellikka PA, Tajik AJ, Khandheria BK, et al. Carcinoid heart disease. Clinical and echocardiographic spectrum in 74 patients. Circulation. 1993: 87(4): 1188-1196, indexed in Pubmed: 7681733

10. Zalecenia ogólne dotyczące postępowania diagnostyczno-terapeutycznego w nowotworach neuroendokrynnych Polskiej Sieci Guzów Neuroendokrynnych 2017.

11. Caowalit N, Conolly HM, Schaff HV, et al. Carcinoid heart disease associated with primary carcinoid heart disease. Am J Med. 1985; 79: 339-354.

12. Robboy SJ, Norris HJ, Scully RE. Insular carcinoid primary in the ovary. A clinicopathologic analysis of 48 cases. Cancer. 1975; 36(2): 404-418, indexed in Pubmed: 1157010. 